\section{Prosimian behavioural ecology}

Ecology and Behaviour of Nocturnal Primates. By P. Charles-Dominique. Pp.x 277 (Duckworth; London; Columbia University Press: New York, 1977.) £12.50; $\$ 21.90$.

THE behavioural ecology of the prosimians, an essential element in our understanding of the evolution of the order of Primates as a whole, raises special problems not encountered in field studies of monkeys and apes. The majority of prosimians are small, shy inhabitants of dense forest environments, solitary in their active phase and, most pertinent here, nocturnal. The task of adequately studying these in the wild is daunting and might seem impossible at times. Yet this book is a measure of just how successfully that task can be carried out.

In the main, it presents the results of almost a decade of research in Gabon in West Africa on five sympatric species of lorisid (three bushbabies, the potto and the angwantibo) living in the equatorial rainforest. Covering in great detail such areas as feeding and diet, stratification, locomotion, defence against predators, and many aspects of social behaviour and demography, it is concerned not simply with each species viewed in isolation but with the vital questions arising from their sympatry. It succeeds in shedding considerable light on the evolution of this group, the adaptive strategies called forth by the particular and precise ecological niches they occupy, the specialisations of structure and behaviour that have developed, and especially the manner in which competition between the species has been minimised.

In most instances, penetrating and wide-ranging analysis leads to wellrounded and convincing synthesis. This has been achieved in two ways: first, by the skilful use of a variety of field techniques, ranging from direct observation with headlamp to capture-markrelease procedures and radio-tracking, the latter yielding some most valuable information. Second, the author repeatedly recognises or finds confirmation of his emergent hypotheses in acute 'casual' observations of untrammelled animals, or in beautifully simple manipulations of the forest environment or captive circumstances.

All this is not to say that CharlesDominique's account of the Gabonese prosimians is complete or without fault. In places, a paucity of hard data, unrevealed sample sizes or the absence of detail when procedures are des- cribed, raise doubts in the mind. The repertoires of communicatory and some other behaviours are incomplete and the social significance of play in lorisids is totally overlooked. Moreover, certain interpretations are suspect or erroneous -for example, that concerning the defensive posture of Arctocebus, and the view that the primary function of the prosimian dental comb is gum collection rather than grooming, despite the indisputable importance of the former function in Euoticus, so clearly shown here.

The title, if not the subtitle of the book could be misleading if, by it, one were led to expect a thorough-going review of our knowledge of all nocturnal primates. In this respect, the work is erratic and there are some surprising omissions, even within the narrower compass of the Lorisidae. A concluding chapter does attempt to place nocturnal primates among the diurnal forms in a wider perspective, but here again the

\section{Sound waves in solids}

Sound Waves in Solids. By H. F. Pollard. Pp. 366. (Pion: London; Academic: London, 1977.) £10.50.

THE author of this latest addition to the rapidly growing literature of acoustics is Dr Howard F. Pollard who is an Associate Professor in charge of the Physical Acoustics Laboratory at the University of New South Wales in Sydney, and is the leading Australian worker in this field. The objective of the author, as indicated in the introduction, is to provide initially the necessary theoretical background for the reader to appreciate fully the various applied fields of acoustics, such as non-destructive testing. This practical aspect is kept well to the fore throughout the book, and uniquely the author introduces, after the basic theory, synopses of experiments which appropriately illustrate the problem under discussion. A particular usefulness of the text to the student is the provision of sets of questions at the end of each chapter which are based on the problems is included at the end of specified sections of the foregoing subject matter. A full set of solutions to the book.

In considering the general contents of the book, it is the chapter on acoustic waveguides on which the author can be particularly congratulated. He has introduced this important topic through the simpler system of a fluid waveguide, and, having established the essential theory and con- quality of the result is decidedly uneven, marred by the dubious validity of a number of contentions regarding Primate evolution and ecology. Thus, the idea that competition for food is necessarily eliminated or even reduced by a Box-and-Cox temporal partitioning of an ecological niche does not stand up to close scrutiny as a general truth.

The strength of this book, and it is indeed strength, lies in the author's approach to, and resolution of, the problems of behavioural ecology in his Gabonese prosimians; and in his demonstration that no aspect or detail of structure or behaviour is arbitrary, without meaning in terms of the animal's survival. That is reason enough to commend this volume.

Gilbert H. Manley

Gilbert H. Manley is Lecturer in Primate Biology in the Department of Anthropology at the University of Durham, UK.

cepts, he deals with the understanding of the various practical applications. The chapter on ultrasonic experimental techniques is quite comprehensive and the latest developments such as ultrasonic spectrometry receive adequate recognition. The author's own research involvement in such work enriches his presentation of the subject; this also applies to the chapter in the book concerned with the exciting field of acoustic visualisation. A representative number of holographic applications are given, and here the author has revealed his musical interests by the inclusion of some reconstructions at audiofrequencies.

The problem of the choice of references is difficult in a field like solidstate ultrasonics, which is large and rapidly expanding, but the author has helped the reader by including the appropriate references at the end of each chapter. Moreover, those concerned with particular experiments are given with the text. An author and a subject index are also included. The line diagrams are very clear and also the text, although the use of smaller print for experimental descriptions gives an impression of over compression.

The title is indicative of the breadth of the subject so efficiently and clearly discussed by the author, and the book deserves to be welcomed alike by students, teachers and research workers.

R. W. B. Stephens

R. W. B. Stephens is Senior Visiting Research Fellow at Chelsea College, University of London, UK. 